\title{
IMPLEMENTASI METODE FIRST IN FIRST OUT (FIFO) UNTUK ANALISA SISTEM ANTRIAN PENGADUAN PELANGGAN INTERNET SERVICE PROVIDER (ISP)
}

\author{
Fajriansyah Noor Hidayat ${ }^{1}$, Imam Husni Al Amin ${ }^{2}$ \\ ${ }^{1,2}$ Program Studi Teknik Informatika, Fakultas Teknologi Informasi, Universitas Stikubank \\ e-mail: ${ }^{1}$ doublank@gmail.com, ${ }^{2}$ imam@edu.unisbank.ac.id
}

\begin{abstract}
Abstrak
Pengaduan sering menjadi salah satu permasalahan di perusahaan yang sangat berpengaruh terhadap kinerja karyawan dan perusahaan. Kurangya perhatian terhadap masalah yang terjadi diperusahaan, baik itu masalah kecil atau besar sangat memprihatinkan. Pada masa sekarang dengan semakin canggihnya teknologi permasalahan seperti pengaduan keluhan dapat diselesaikan dan diproses secara cepat. Untuk membantu konsumen yang mengalami masalah dan mengutarakan keluhannya melalui pengaduan. Maka dari itu dibuatlah Queue System Pengaduan Pelanggan Internet Service Provider (ISP) Menggunakan Metode First In First Out (FIFO) yang bertujuan untuk memudahkan pelanggan untuk melakukan pengaduan dan menyampaikannya kepada perusahaan. Sistem ini dibuat dengan menggunakan bahasa pemrograman PHP. Hasil dari penelitian ini adalah Sistem antrian pengaduan (Queue System) yang dapat memproses pengaduan pelanggan.
\end{abstract}

Kata Kunci: Pengaduan, Sistem Antrian, Metode First in First Out, FIFO, First In First Out

\section{PENDAHULUAN}

Di Indonesia, teknologi dalam bidang pelayanan bukan merupakan hal baru yang menjadi perhatian kita. Karena setiap waktu ke waktu perkembangan teknologi di Negara Indonesia semakin maju. Banyaknya berbagai permasalahan dapat diselesaikan oleh bantuan peran teknologi. Hal tersebut menjadi sangat penting untuk mendongkrak berbagai aspek penyelesaian masalah itu sendiri. Pemanfaatan teknologi informasi memang sangat penting. Pada dasarnya sebuah perusahaan yang memanfaatkan teknologi informasi secara optimal yang dapat bertahan dalam era global ini, karena lewat pemanfaatan teknologi informasi perusahaan dapat mengaskses informasi dengan cepat, tepat dan akurat serta dapat memberikan pelayanan yang efektif dan efisien. Informasi sendiri merupakan hal yang sangat penting peranannya dalam menunjang jalannya keseimbangan perusahaan demi tercapainya tujuan yang di inginkan [13]. Banyak dari berbagai pekerjaan yang membutuhkan teknologi informasi untuk mendampingi para pekerja mendapatkan pencapaian lebih. Memang sedemikian rupa dibuat untuk memecahkan berbagai permasalahan yang ada, salah satunya adalah sistem antrian. Antrian merupakan hal yang masih menjadi permasalahan dan permasalahan ini terjadi pada saat kemampuan menyelenggarakan layanan lebih kecil dibandingkan dengan kebutuhan layanan [27].

Hingga saat ini masih banyak pelanggan yang mengeluh karena manajemen dan sistem antrian masih kurang atau belum terorganisir oleh perusahaan. Perusahaan membutuhkan bantuan teknologi seperti sebuah aplikasi yang dapat meningkatkan kepuasan pelanggan. Kualitas pelayanan perlu mendapat perhatian besar dari perusahaan, karena kualitas pelayanan mempunyai hubungan langsung dengan kemampuan bersaing dan tingkat keuntungan perusahaan[8]. Aplikasi untuk sistem antrian sendiri merupakan wujud dari teknologi informasi yang membantu dalam menata, memilah, memproses serta memberikan informasi kepada Pelanggan. Dengan Pelanggan dan perusahaan sebagai element yang saling berhubungan. Informasi tentang pelanggan dan hal yang berkaitan tentang keuntungan yang di dapatkan oleh pelanggan di sampaikan melalui aplikasi mobile pelanggan. Dengan aplikasi mobile yang dapat di akses, memungkinkan user lebih sering mengakses serta fitur dan user interface yang memudahkan untuk user. Dengan begitu perusahaan dapat mempersingkat waktu antrian pembayaran serta klaim tentang pengaduan pelanggan. Dalam sistem metode First In First Out atau FIFO merupakan salah satu cabang logika pemecahan masalah yang 
menggunakan basis data standar. Metode FIFO di deskripsikan ialah metode penilaian pelayanan dimana yang lebih dahulu masuk maka lebih dahulu keluar atau yang lebih dahulu datang maka lebih dahulu dilayani. Dengan metode FIFO pelayanan dapat segera diproses dan diselesaikan sehingga dengan metode ini kualitas pelayanan pada perusahaan akan tetap terjaga tanpa harus menunggu lama. Oleh karena itu akan di buatnya queue system pengaduan pelanggan Internet Service Provider (ISP) menggunakan metode First In First Out (FIFO). Untuk mengurangi tingkat permasalahan pengaduan dan membantu meningkatkan pelayanan serta membuat pendapat pelanggan menjadi lebih baik lagi. Pada umumnya perusahaan menggunakan metode ini, sebab sebagian besar sistem menggunakan aturan antrian yang disebut aturan first in first out dimana pelanggan yang datang lebih dahulu dialah yang pertama dilayani [12].

Sehubung dengan permasalahan tersebut, maka penulis mengambil judul "Queue System Pengaduan Pelanggan Internet Service Provider (ISP) menggunakan metode first in first out (FIFO)" sehingga dapat membantu pelayanan kepada pelanggan.

\section{METODE PENELITIAN}

\subsection{First In First Out (FIFO)}

First-In First-Out(FIFO) adalah sebuah metode pemecahan dalam masalah antrian yang dapat diterapkan dengan cara laporan pengaduan yang pertama kali masuk diasumsikan keluar pertama kali. Jika laporan pengaduan yang dikeluarkan maka akan diselesaikan yang pertama. Hal ini sudah berjalan sesuai dengan alur arus antrian dimana sudah sepantasnya laporan pengaduan yang pertama kali mauk akan diselesaikan pertama kali dahulu. Adapun menurut Kemal Nasir dan Renggo Pribadi [21]Algoritma First In First Out adalah sebuah algoritma untuk menerapkan disiplin antrian yang tidak berprioritas. Algoritma ini menggunakan struktur data. Algoritma FIFO sering di gunakan di berbagai macam pemecahan masalah kehidupan dan berbagai aplikasi serta teknologi yang ada. FIFO sendiri merupakan algoritma yang bersifat berurutan dan bergiliran namun tetap pada alur atau jalurnya sesuai dengan yang pertama kali masuk dan kemudian diproses sesuai dengan giliran. Berikut adalah gambar algoritma FIFO :

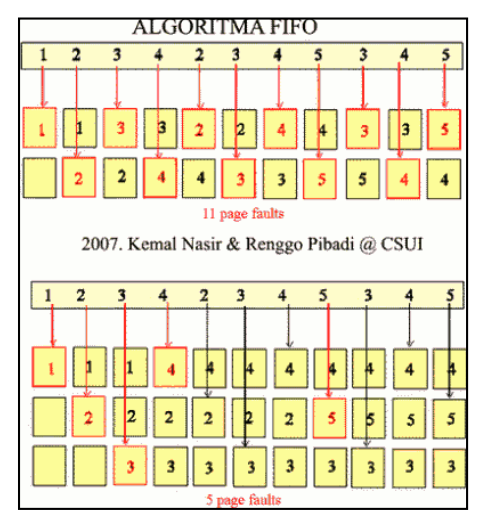

Gambar 1. Algortima First In First Out

Untuk membuat rancangan, sistem ini menggunakan UML sebagai bahasa pemodelan yang terdiri dari Class Diagram, Use Case Diagram, Activity Diagram, Squance Diagram. UML (Unified Modelling Language) adalah suatu alat untuk memvisualisasikan dan mendokumentasikan hasil analisa dan desain yang berisi dalam memodelkan sistem secara visual.

\section{Use Case Diagram}

Use Case digunakan untuk membuat visualisasi rancangan pengembangan sebuah software atau sistem informasi yang menjelaskan kebutuhan fungsional dari sistem yang bersangkutan. Dalam gambar Use Case dapat dilihat bahwa pengguna dapat melihat halaman home, daftar baru, pengaduan, biaya pasang/biaya bulanan, daftar paket internet, pendaftar terbaru, informasi dan login, apabila pengguna ingin melakukan pengaduan, pengguna tidak diharuskan untuk login terlebih dahulu dan harus memiliki id pelanggan yang terdaftar. Kemudian saat pengguna ingin melakukan login,pengguna harus mendaftar terlebih dahulu dan membuat akun baru. Dan apabila calon pengguna 
mendaftar baru melalui antarmuka awal, pengguna harus menghubungi pihak perusahaan untuk mengaktifkan akun dan mendapatkan id pelanggan.

Untuk masuk kedalam halaman admin, diharuskan untuk login menggunakan akun admin terlebih dahulu. Setelah admin melakukan login maka akan mendapatkan hak akses untuk melihat dan memproses pengaduan, mengisi profil antarmuka, membuat akun, mengisi dan mengubah daftar harga serta paket internet, mencetak pengaduan, data pelanggan, dan harga paket. Berikut adalah Use Case diagram yang dibuat untuk program Queue System Pengaduan Pelanggan Internet Service Provider (ISP) Menggunakan Metode First In First Out (FIFO).

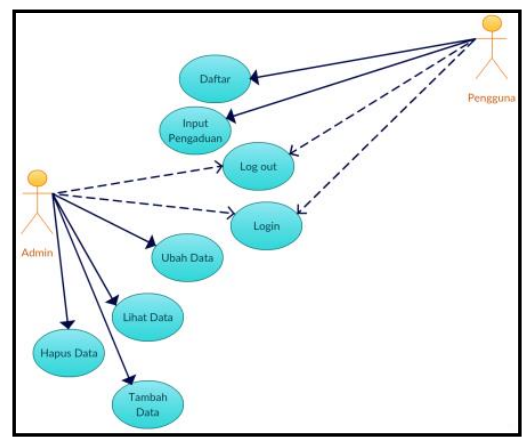

Gambar 2. Use Case Diagram Pengguna dan Admin

\section{Class Diagram}

Class Diagram yang menggambarkan hubungan antara class dengan objek satu sama lain.berikut adalah class diagram Queue System Pengaduan Pelanggan Internet Service Provider (ISP) Menggunakan Metode First In First Out (FIFO) :

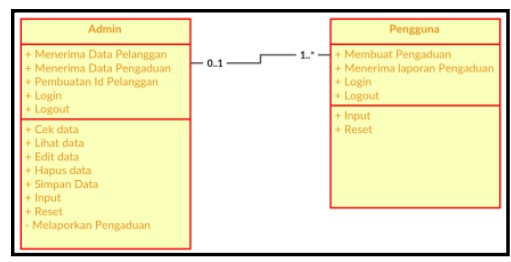

Gambar 3. Class Diagram Queue System Pengaduan

\section{Activity Diagram}

Diagram activity merupakan diagram yang menggambarkan secara visual dimana admin memulai dengan menu login (masuk). Kemudian admin mengisi form login (masuk) agar dapat masuk ke sistem dibuat. Jika admin telah masuk ke dalam menu utama, admin dapat memilih menu yang tersedia di dropdown pilihan menu yang ada. Berikut ini merupakan diagram activity login admin :

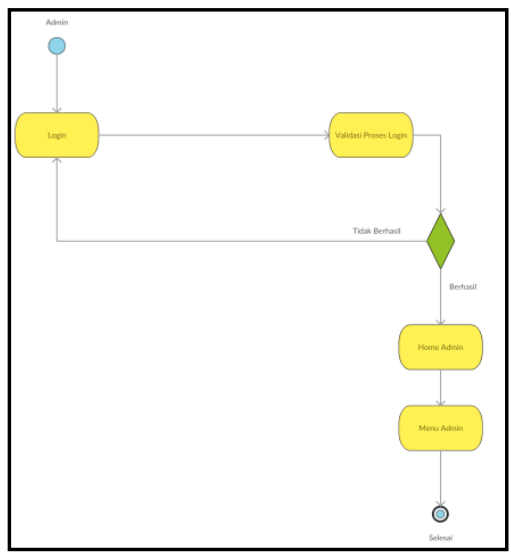

Gambar 4. Diagram Activity Login Admin 


\section{Sequence Diagram}

Sequence diagram menjelaskan perilaku objek yang berada di use case secara visual. Berikut adalah gambar diagram sequence:

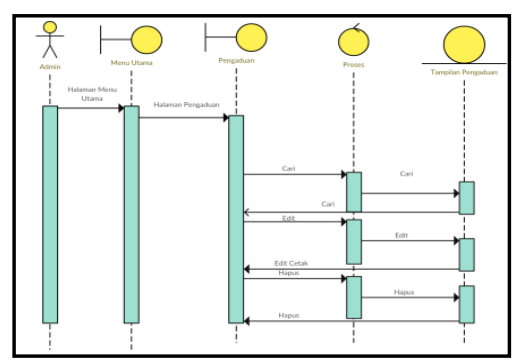

Gambar 5. Diagram Sequence Menu Pengaduan

\section{HASIL DAN PEMBAHASAN}

Pengujian dilakukan oleh peneliti agar dapat mengetahui apakah program yang dibuat berjalan dengan baik dan sesuai dengan harapan. Berikut ini adalah hasil pengujian yang telah dilakukan

\subsection{Daftar Baru pada Tampilan Awal}

Daftar baru pada tampilan awal yang akan memberikan output setelah mengisi form dan kemudian meng-input data. Jika calon pelanggan berhasil melakukan input, maka akan ada pemberitahuan dari sistem seperti pada gambar sebagai berikut :

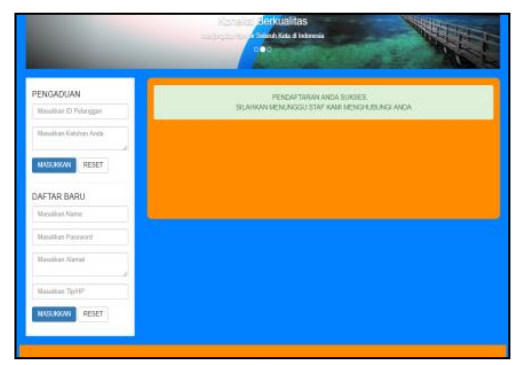

Gambar 6. Berhasil Mendaftar Akun Pelanggan Baru

Setelah berhasil mendaftar baru, akun tidak dapat langsung dipergunakan karena belum memiliki ID pelanggan yang dipergunakan untuk login pelanggan seperti pada gambar berikut :

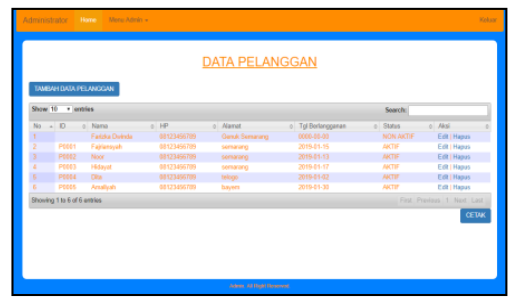

Gambar 7. Akun baru terdaftar

Dapat dilihat pada gambar 7 data dan informasi yang di input oleh calon pelanggan, belum memiliki ID pelanggan dan tanggal berlangganan. Untuk itu admin melakukan proses pemberian ID pelanggan kepada akun yang baru terdaftar tersebut seperti pada gambar berkut ini

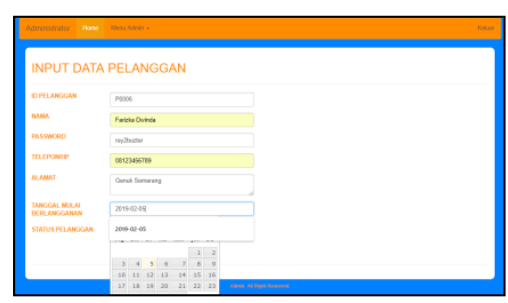

Gambar 8. Proses Pemberian ID 
Setelah pemberian ID pelanggan dan tanggal berlangganan akun perlu di aktifkan oleh admin agar dapat dipergunakan calon pelanggan tersebut menjadi aktif dari yang sebelumnya non aktif. Jadi untuk calon pelanggan yang ingin mempergunakan akun yang dibuatnya setelah mendaftar baru, harus menghubungi admin untuk mengaktifkan akun yang baru saja dibuat.

Untuk melakukan pengaduan, sebagai seorang pelanggan yang akan mengajukan keluhan atau melakukan pengaduan. Pelanggan harus memiliki ID pelanggan untuk melakukan pengaduan. Karena ketika hendak mengisi form pengaduan pelanggan diwajibkan mengisi ID pelanggan yang sudah terverifikasi oleh admin (Aktif dan terdaftar). Berikut gambar Form Pengaduan yang perlu di isi pelanggan :

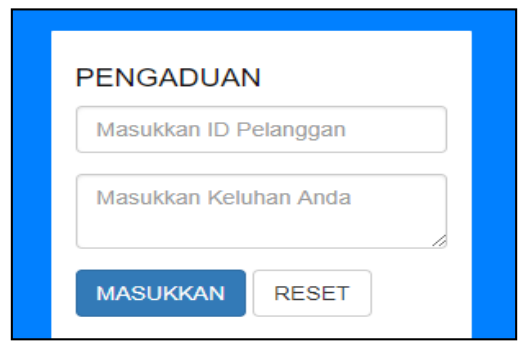

Gambar 9. Form Pengaduan

Queue System Pengaduan

Sistem yang dibuat peneliti adalah Queue System Pengaduan Pelanggan Internet Service Provider (ISP) Menggunakan Metode First In First Out (FIFO). Sesuai dengan judul yang dibuat peneliti, program ini memproses pengaduan yang masuk dengan menggunakan metode first in first out. Berikut gambar hasil uji coba program yang dilakukan peneliti :

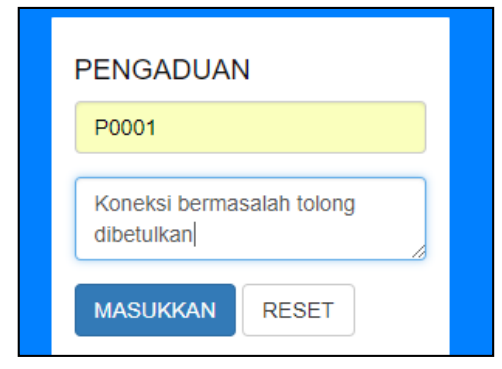

Gambar 10. Input Pengaduan

Setelah mengisi form seperti pada gambar 10 maka pengaduan akan masuk kedalam list pengaduan yang ada pada admin. Keluhan telah di terima dan tinggal menunggu diproses. Kemudian keluhan yang tadi telah di-input akan masuk kedalam list pengaduan admin

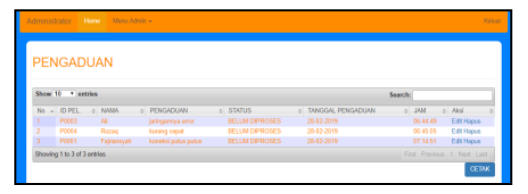

Gambar 11. List Pengaduan Yang Masuk

Pada gambar 11 terlihat dengan status belum di proses. Maka dari itu metode first in first out yang dibuat oleh peneliti diterapkan pada sistem mengacu pada tanggal pengaduan dan jam pengaduan. First in first out sendiri berarti yang pertama kali masuk, jika ada. pengaduan berikutnya yang masuk maka pengaduan yang pertama tersebut yang akan tetap di proses duluan oleh sistem. Berikut gambar dan pembahasan penerapan metode first in first out pada Queue System Pengaduan Pelanggan Internet Service Provider (ISP) Menggunakan Metode First In First Out (FIFO) yang dibuat peneliti : 


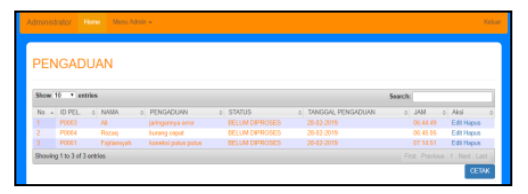

Gambar 12. List Pengaduan Masuk dan Belum di Proses

Sebelum proses perubahan status menjadi sudah diproses. Admin akan melihat apabila ada konfirmasi pelanggan bahwa proses pengaduan atau keluhan sudah mendapat konfirmasi dari pelanggan. Maka admin akan merubah status yang "BELUM DI PROSES" menjadi "SUDAH DI PROSES". Kemudian setelah proses pelanggan melakukan konfirmasi pengaduan, maka admin akan masuk kedalam menu edit pengaduan untuk melakukan perubahan status pengaduan. Kemudian pengaduan yang kedua yang belum di proses akan dirubah status prosesnya.

Pada list pengaduan masuk yang pertama dan kedua ketika telah dilakukan pemrosesan (Update) pengaduan tersebut akan turun kebawah dan menyesuaikan dengan metode first in first out yang terapkan peneliti didalam sistem. Berikut gambar status pengaduan, tanggal, dan jam tempat di terapkannya metode first in first out.

Cetak

Pada program yang dibuat peneliti yaitu Queue System Pengaduan Pelanggan Internet Service Provider (ISP) Menggunakan Metode First In First Out (FIFO) terdapat tombol cetak yang berfungsi untuk mencetak data yang ada didalam list. Didalam program yang dibuat peneliti cetak hanya berada didalam menu Pengaduan, Pelanggan dan Harga.

\section{KESIMPULAN}

Dari uraian yang telah dijelaskan sebelumnya, maka dapat diambil suatu kesimpulan :

Sistem Antrian Pengaduan Pelanggan Internet Service Provider (ISP) Menggunakan Metode First In First Out (FIFO) dapat dipergunakan untuk membantu masalah pelayanan dibagian pengaduan.

Program yang dibuat peneliti dapat memberikan efisiensi terhadap pelayanan pelanggan. Seperti mengurangi antrian tunggu secara offline, meningkatkan tingkat mobilitas kinerja karyawan yang bersangkutan dengan pengaduan dan pemrosesan keluhan, serta menata dan memanajemen secara rapi pengaduan - pengaduan dan keluhan yang ditujukan kepada perusahaan untuk segera diselesaikan.

\section{DAFTAR PUSTAKA}

[1] Taha, Hamdy. 2007, Operation Research : An Introduction, Edisi ke-8, Prentice Hall

[2] Aji, Dwi N, I. H. Al Amin. (2018) Aplikasi CRM Pada Anto Stationery Dengan Metode First In First Out Berbasis Web Mobile, ISBN: 978-602-8557-20-7

[3] Arief M Rudianto. 2011. Pemrograman Web Dinamis menggunakan PHP dan MySQL. C.V ANDI OFFSET. Yogyakarta.

[4] Arman Hakim Nasution. 2006. Manajemen Industri. Yogyakarta: Andi Offset.

[5] Booch, G. James, R. Ivar, J, 2005. The Unified Modeling Language User Guide Second Edition. United State: Addison Wesley Professional

[6] Bell, S., \& Luddington ,J. (2006) Coping With Customer Complaints. Journal Of Service Research.

[7] Davis, G.B. 1991. Kerangka Dasar Sistem Informasi Manajemen Bagian 1. Jakarta: PT Pustaka Binamas Pressindo

[8] Efendi, Januar P, Lili A.Yuliati. (2016) Pengaruh Kualitas Terhadap Pelayanan Pada JNE Cabang Bandung, Bandung, September.

[9] Firmansyah, Cahya, Tohir, Cucu.S. (2018) Sistem Layanan Pengaduan Masyarakat Lingkup Desa Gunung Tanjung Berbasis Web Dan SMS Gateway Dengan Metode Antrian FIFO, Tasikmalaya, PISSN: 2613-9138 - EISSN : 2613-9146. 
[10] Greenberg, P. 2010. Customer Relationship Management as the Speed of Light: Fourth Edition McGraw-Hill.

[11] Hasan, Irmayanti. (2011) Model Optimasi Pelayanan Nasabah Berdasarkan Metode Antrian (Queuing System), Malang, Januari.

[12] Heizer, Jay dan Rander, Barry. 2006. Manajemen Operasi (Edisi Ketujuh). Salemba Empat, Jakarta.

[13] Hendrik, I.D.W. (2017) Sistem Informasi Pembayaran SPP pada SMK Pawyatan Daha 3 Kediri, Kediri, 14 Agustus 2017.

[14] Indrajani. 2011. Perancangan Basisdata dalam All in 1, Jakarta: PT. Elex Media Komputindo.

[15] Indrajit, 2001, Analisis dan Perancangan Sistem Berorientasi Object. Bandung, Informatika 